\title{
PENGENALAN MUDAHNYA BERKREASI VIDEO GAYA ATRAKTIF PADA GENERASI MILENIAL
}

\author{
Maruloh $^{1}$, Dikdik Permana Wigandi², Agus Yulianto ${ }^{3}$ \\ 1,2,3 Teknik Informatika, STMIK Nusa Mandiri \\ Jl. Jatiwaringin Raya No.02, Kecamatan Makasar Jakarta Timur \\ 11maruloh@nusamandir.ac.id, 2dikdik.pw@nusmanadiri.ac.id, 3agus.yulianto@nusamandiri.ac.id
}

\begin{abstract}
We are Social survey states that 150 million Indonesians actively use social media From various social media, Youtube is the most accessed platform, which is around 88\% of social media users in 2019. Youtube is the most accessed social media by the millennial generation. During its development, the term creator content emerged. Content creators are people whose profession is to create content, whether in the form of writing, images, videos, or sound. Content using video is one of the most popular today. Many children and teenagers are interested in video content applications. This community service activity is located in RPTRA Alur Dahlia with the target of participating children and adolescents of RPTRA Alur Dahlia, which is located in RT 2 RW 7, Tegal Alur Village, West Jakarta. The problem that can occur in children and adolescents there is the intensity or frequency of children and adolescents opening Youtube or applications with video content. Whether it's for viewing or they create video content to upload. Therefore, they need guidance and training on how to make video content that is not only interesting but also educational and useful for others. From these problems, we carried out community service activities at RPTRA Alur Dahlia so that the children there could be more open-minded about the rules for making video content and be able to make videos that were useful and useful for the community.
\end{abstract}

Keywords: Video Creation, Millennial Generation, RPTRA Alur Dahlia

\begin{abstract}
Abstrak
Survei We are Social menyebutkan 150 juta penduduk Indonesia aktif menggunakan media sosial. Dari beragam medsos, Youtube menjadi platform yang terbanyak diakses yaitu sekitar $88 \%$ dari pengguna medsos pada tahun 2019. Youtube menjadi medsos yang paling banyak diakses oleh generasi milenial. Dalam perkembangannya, munculah istilah konten kreator. Konten kreator merupakan orang yang berprofesi untuk membuat suatu konten, baik berupa tulisan, gambar, video, atau suara. Konten dengan menggunakan video merupakan salah satu yang paling popular saat ini. Banyak anak-anak dan remaja yang tertarik dengan aplikasi berkonten video. Kegiatan pengabdian masyarakat ini berlokasi di RPTRA Alur Dahlia dengan target peserta anak-anak dan remaja RPTRA Alur Dahlia, yang berlokasi di RT 2 RW 7, Kelurahan Tegal Alur Jakarta Barat. Permasalahan yang bisaa terjadi pada anak-anak dan remaja disana adalah intensya atau seringnya anak-anak dan remaja membuka Youtube atau aplikasi yang berkonten video. Entah itu untuk sekedar melihat atau mereka membuat konten video untuk diupload. Oleh karena itu perlu bimbingan dan pelatihan kepada mereka bagaimana membuat konten video yang tidak hanya menarik, tetapi juga mendidik dan bermanfaat untuk sesama. Dari permasalahan tersebut, kami melakukan kegiatan pengabdian masyarakat di RPTRA Alur Dahlia agar anak-anak disana bisa lebih terbuka wawasannya mengenai aturan pembuatan konten video dan mampu membuat video yang bermanfaat dan berguna untuk masyarakat.
\end{abstract}

Kata Kunci: Kreasi Video, Generasi Milenial, RPTRA Alur Dahlia.

\section{PENDAHULUAN}

Kemajuan dan perkembangan dalam penggunaan perangkat lunak dan perangkat keras dikehidupan sehari-hari membawa kita dalam kehidupan yang maju. Keahlian dan kemampuan diri memiliki dampak yang baik untuk membantu menyelesaikan pekerjaan-pekerjaan manusia. Bagi seorang dosen kegiatan Tridharma Perguruan Tinggi yang wajib dilaksanakan setiap Perguruan Tinggi adalah Pendidikan, Penelitian, dan Pengabdian Masyarakat [1].

Di jaman perkembangan teknologi saat ini [2], teknologi diharapkan bukan hanya untuk hiburan melainkan juga untuk pendidikan [3], begitupula dengan perangkat lunak seperti 
Youtube ataupun TikTok. Youtube adalah media platform yang dimiliki oleh Google sebagai media yang menyediakan konten visual berupa video tak terbatas oleh waktu [4].

Sedangkan TikTok merupakan perangkat lunak yang menyediakan konten berupa visual namun dibatasi oleh waktu dan disertai dengan berbagai fitur yang memungkinkan penggunanya untuk mempercantik konten yang ada. Dan berdasarkan survey yang dilakukan oleh We are Social [5] menyebutkan 150 juta penduduk Indonesia aktif menggunakan media sosial (medsos).

Dari beragam medsos, Youtube menjadi platform yang terbanyak diakses yaitu sekitar $88 \%$ dari pengguna medsos pada tahun 2019 [6] . Youtube menjadi medsos yang paling banyak diakses oleh generasi milenial [7]. Tidak bisa dipungkiri, generasi milenial memiliki keterikatan kuat dengan teknologi, mereka sangat menyukai hal-hal visual, serta cenderung merasa bosan. Teknologi seakan sudah mendarah daging pada diri setiap generasi milenial [8].

Dalam perkembangannya, munculah istilah konten kreator [9]. Konten kreator merupakan orang yang berprofesi untuk membuat suatu konten, baik berupa tulisan, gambar, video, atau suara [10]. Konten dengan menggunakan video merupakan salah satu yang paling popular saat ini. Banyak anak-anak dan remaja yang tertarik dengan aplikasi berkonten video tidak sedikit pula anak-anak dan remaja yang memiliki channel di Youtube atau bahkan tik-tok untuk mengekspresikan diri mereka [11]. Jika dilihat dari dampaknya, anak-anak dan remaja hendaknya memiliki aturan model agar konten video yang mereka buat tidak hanya atraktif, tapi juga bisa memberikan manfaat dan inspirasi bagi masyarakat.

Dalam pelaksanaanya, Kegiatan pengabdian masyarakat ini berlokasi di RPTRA Alur Dahlia dengan target peserta anak-anak dan remaja RPTRA Alur Dahlia, yang berlokasi di RT 2 RW 7, Kelurahan Tegal Alur Jakarta Barat. Permasalahan yang bisaa terjadi pada anak-anak dan remaja disana adalah intensya atau seringnya anak-anak dan remaja membuka Youtube atau aplikasi yang berkonten video. Entah itu untuk sekedar melihat atau mereka membuat konten video untuk diupload. Oleh karena itu perlu bimbingan dan pelatihan kepada mereka bagaimana membuat konten video yang tidak hanya menarik, tetapi juga mendidik dan bermanfaat untuk sesama.

Dari permasalahan tersebut, kami melakukan kegiatan pengabdian masyarakat di
RPTRA Alur Dahlia agar anak-anak disana bisa lebih terbuka wawasannya mengenai aturan pembuatan konten video dan mampu membuat video yang bermanfaat dan berguna untuk masyarakat.

\section{METODE PENGABDIAN MASYARAKAT}

1. Bentuk Kegiatan

Bentuk kegiatan adalah berupa seminar bagaimana peserta membuat video atraktif agar bisa mengapresiasikan diri dengan baik dan berguna dan bermanfaat untuk masyarakat.

2. Pelaksanaan

Pengabdian masyarakat ini diadakan pada Sabtu, 21 Maret 2020 pukul $10.00-12.00$ WIB yang bertempat di RPTRA Alur Dahlia, RT 2 RW 7, Kelurahan Tegal Alur, Jakarta Barat

3. Tahapan Kegiatan

Tahapan pengabdian yang dilaksanakan adalah sebagai berikut:

a. Analisa Lingkungan

Analisa lingkungan dimkasudkan sebagai kegiatan penentuan lokasi kepada objek pelaksanaan pengabdian masyarakat. Objek yang dituju dalam penelitian ini yaitu anakanak dan remaja dilingkungan RPTRA Alur Dahlia Rt/Rw 02/07, kelurahan tegal alur, Jakarta barat.

b. Persiapan Kegiatan

Persiapan kegiatan meliputi pembuatan modul ajar dan materi yang akan disampaikan.

c. Pembuatan Proposal

Pembuatan proposal meliputi estimasi biaya, untuk kebutuhan akomodasi perjalanan, peralatan, perlengkapan, biaya ATK dan biaya lainnya seperti souvenir dan biaya tak terduga.

d. Pelaksanaan Kegiatan

Audiansi untuk pelaksanaan kegiatan ini yaitu anak-anak dan remaja RPTRA Alur Dahlia yang melakukan kegiatan ini ditempat RPTRA Alur Dahlia dan setelah kegiatan selesai, para peserta ini mengisi kuesioner secara online yang dibuat menggunakan Google Form.

\section{e. Laporan Kegiatan}

Laporan kegiatan ini merupakan bentuk pertanggung jawaban kegiatan yang telah dilaksanakan. Laporan tersebut meliputi laporan kegiatan pengabdian masyarakat termasuk laporan keuangan. Pembuatan press realease kegiatan yang diunggah pada website umum agar dapat dibaca oleh masyarakat umum.

Untuk presss realease dapat dilihat dilaman: https://www.kompasiana.com/agusyul/5e96b badd541df4adc168bd3/pengenalan- 
mudahnya-berkreasi-video-gaya-aktraktifpada-generasi-millennial

4. Tahapan Penjurnalan

Pembuatan jurnal pengabdian masyarakat merupakan pilihan tambahan sebagai hasil dari kegiatan pengabdian masyarakat ini.

Pelaksanaan kegiatan ini berupa seminar disampaikan dengan ceramah dengan ditunjang diskusi dan tanya jawab serta demonstrasi.

\section{HASIL DAN PEMBAHASAN}

\section{Pelaksanaan Kegiatan}

Dalam pelaksanaan kegiatan ini, tak luput kami meminta ijin kepada pemerintah setempat seperti gambar 1, sehingga kegiatan dapat dijalankan dengan baik dan mendapat ijin resmi.

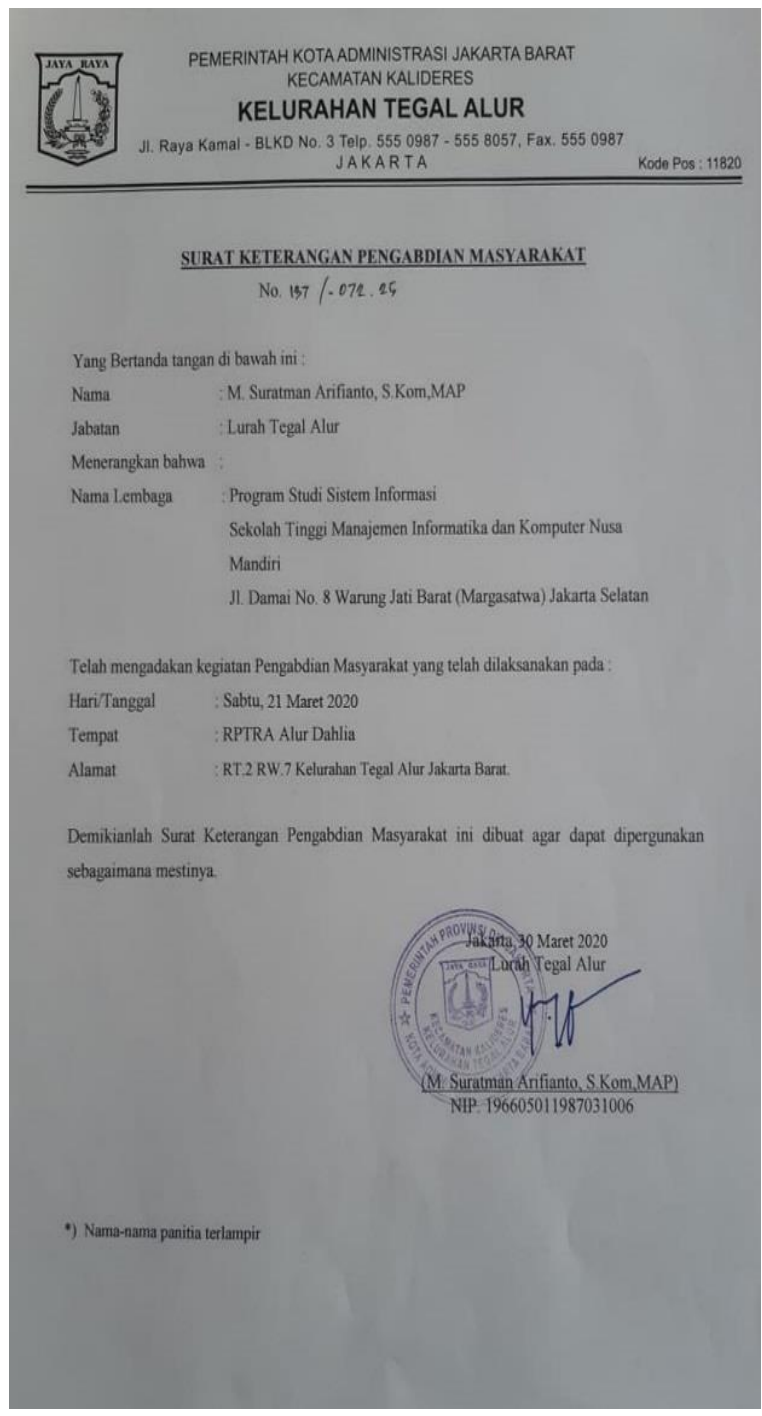

Gambar 1. SK Pengabdian Masyarakat
Pelaksanaan dimulai dengan tutor melakukan pembukaan dan memberikan materi kepada peserta seperti terlihat pada gambar 2 .

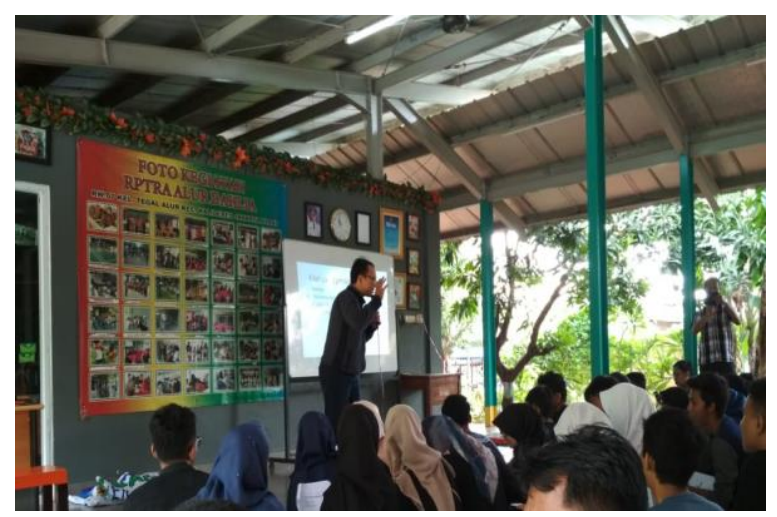

Gambar 2. Tutor memberikan materi kepada peserta

Kemudian peserta juga diajak langsung untuk partisipasi dan melakukan diskusi dengan tutor perihal materi, seperti terlihat pada gambar 3 .

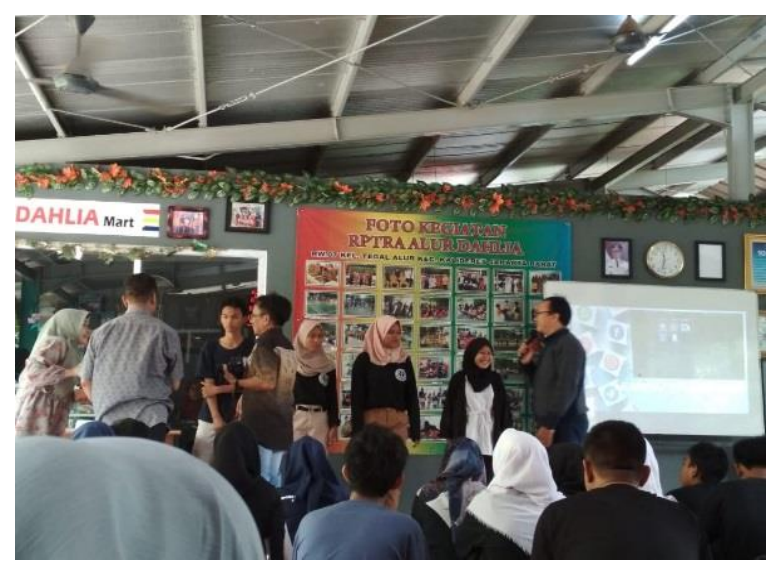

Gambar 3. Diskusi interaktif dengan peserta

Dalam pelaksanaan berjalan dengan baik yang terlihat seperti gambar 4 dimana peserta begitu antusias dalam memperhatikan tutor dalam menyampaikan materi.

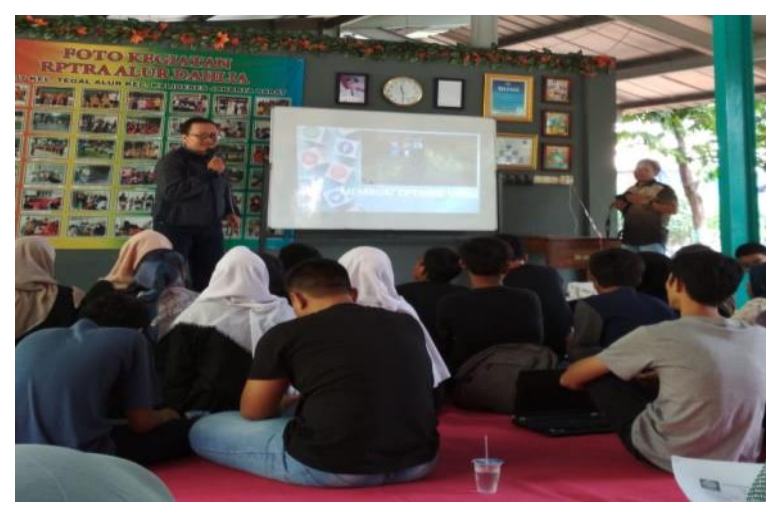

Gambar 5. Antusiasme peserta dalam mendengarkan tutor 
Kemudian dalam pelaksanaan juga peserta dipersilahkan untuk bertanya dan diskusi, seperti terlihat pada gambar 5 dimana ada salah satu peserta bertanya kepada tutor perihal materi.

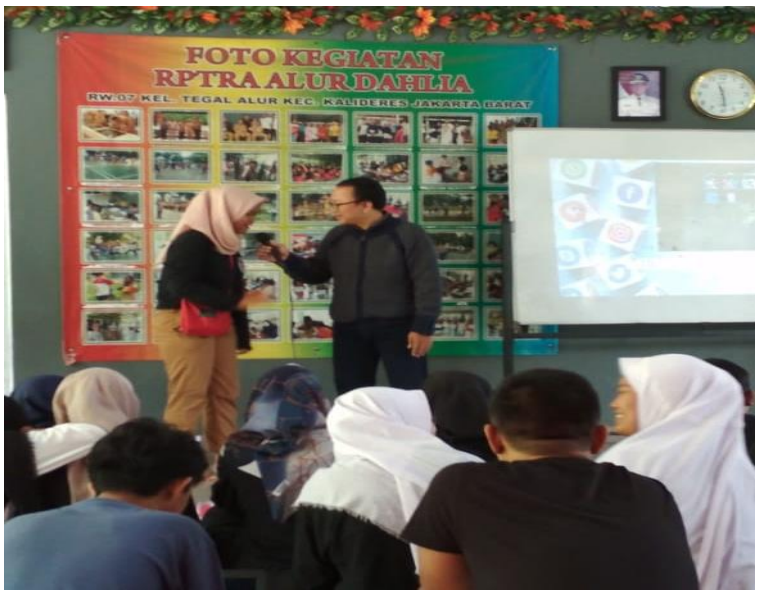

Gambar 5. Tanya jawab dengan peserta

Setelah acara berlangsung dilakukan juga foto bersama sebagai dokumentasi akhir dan acara pun berjalan dengan baik dan lancar.

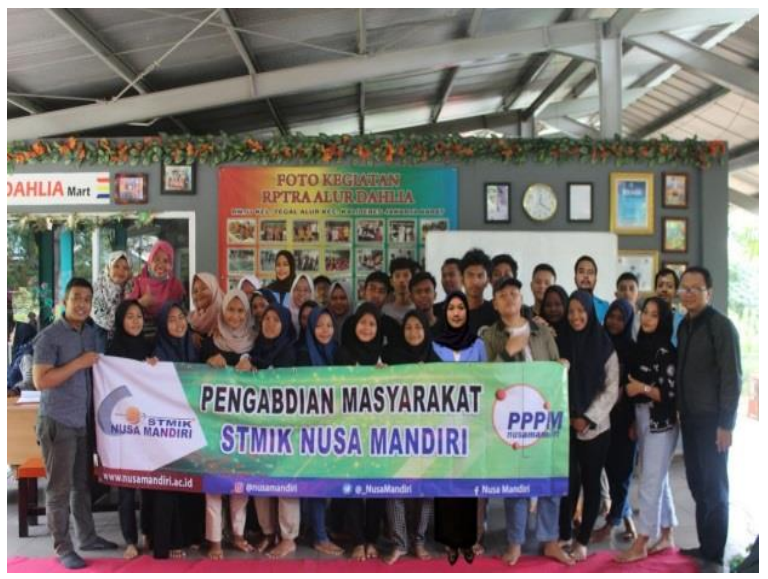

Gambar 6. Foto bersama dengan peserta

Peserta mendapatkan ilmu baru serta tips dan trik untuk berkreasi video atraktif yang edukatif dan bermanfaat. Pesertapun diberikan kuesioner yang disebarkan via Google Form guna untuk mendapat respon atas pelaksanaan pelatihan dengan total responden sebanyak 22 orang.

Terdapat 10 pertanyaan dalam kuesioner tersebut, seperti terlihat pada tabel 1:

Tabel 1. Kuesioner Peserta

\begin{tabular}{cl}
\hline Kode & \multicolumn{1}{c}{ Pertanyaan } \\
\hline P1 & $\begin{array}{l}\text { Personil/anggota yang terlibat dalam kegiatan } \\
\text { pengabdian masyarakat memberikan } \\
\text { pelayanan sesuai dengan kebutuhan peserta }\end{array}$ \\
\hline P2 & $\begin{array}{l}\text { Tutor menyampaikan materi kegiatan dengan } \\
\text { jelas dan mudah dimengerti oleh peserta }\end{array}$ \\
\hline
\end{tabular}

\begin{tabular}{cl}
\hline Kode & \multicolumn{1}{c}{ Pertanyaan } \\
\hline P3 & $\begin{array}{l}\text { Setiap keluhan/pertanyaan/permasalahan } \\
\text { yang diajukan ditindaklanjuti dengan baik } \\
\text { oleh tutor yang terlibat }\end{array}$ \\
\hline P4 & $\begin{array}{l}\text { Materi yang disampaikan sesuai dengan } \\
\text { kebutuhan peserta dalam menambah } \\
\text { wawasan, pengetahuan, keterampilan dan } \\
\text { keahlian peserta }\end{array}$ \\
\hline P5 & $\begin{array}{l}\text { Peserta mendapatkan materi kegiatan berupa } \\
\text { modul dan soal latihan }\end{array}$ \\
\hline P6 & $\begin{array}{l}\text { Peralatan untuk menyampaikan materi } \\
\text { memadai }\end{array}$ \\
\hline P7 & $\begin{array}{l}\text { Kegiatan pengabdian masyarakat yang } \\
\text { disampaikan bermanfaat untuk menambah } \\
\text { wawasan, pengetahuan, keterampilan dan } \\
\text { keahlian peserta }\end{array}$ \\
\hline P8 & $\begin{array}{l}\text { Saya merasa puas dengan kegiatan } \\
\text { pengabdian masyarakat yang diselenggarakan } \\
\text { STMIK Nusa Mandiri }\end{array}$ \\
\hline P9 & $\begin{array}{l}\text { Kegiatan pengabdian masyarakat yang } \\
\text { diselenggarakan STMIK Nusa Mandiri sesuai } \\
\text { dengan harapan saya }\end{array}$ \\
\hline P10 & $\begin{array}{l}\text { Jika kegiatan ini diselenggarakan kembali, } \\
\text { saya bersedia untuk berpartisipasi/terlibat }\end{array}$ \\
\hline
\end{tabular}

\section{Monitoring Dan Evaluasi}

Tahap ini adalah untuk melakukan evaluasi dan meninjau ulang dari kegiatan pengabdian masyarakat. Evaluasi berupa kalkulasi dari pengisian kuesioner. Setelah melakukan analisa di Excel [12] dengan 10 pertanyaan dari 22 responden yang menjawab puas atau tidak puas tersebut disimpulkan hasil:

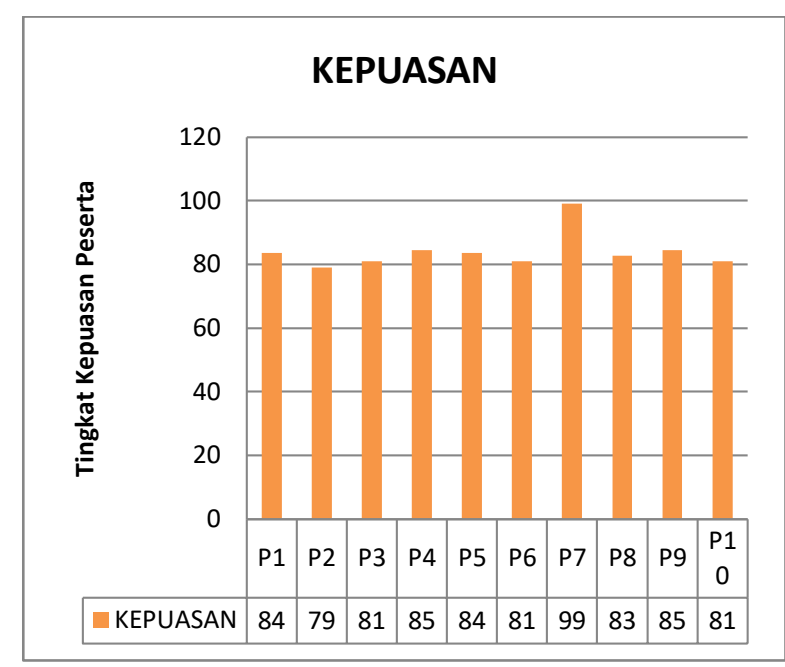

Gambar 7. Presentase Responden

Terlihat pada gambar 7, bahwa untuk P1 tentang materi sesuai kebutuhan atau tidak, semua peserta menjawab puas sehingga hasil untuk P1 adalah $100 \%$ begitupula untuk P2 semua 
peserta menjawab puas tentang penyampaian tutor yang mudah dimengerti sehingga hasil untuk P2 adalah 100\% lalu untuk P3 semua peserta menjawab puas juga perihal setiap pertanyaan dapat dijawab dengan baik oleh tutor sehingga hasil untuk P3 adalah 100\% dan P4 pun hasilnya $100 \%$ perihal materi sesuai kebutuhan atau tidak dari 22 peserta, namun untuk P5 telihat hanya $82 \%$ yang berarti hanya 18 orang yang puas, 4 orang menjawab tidak puas tentang materi berupa modul dan soal latihan yang didapat atau tidak, namun untuk P6 semua peserta menjawab puas terkait kelengkapan peralatan dalam menyampaikan materi sehingga hasil untuk P6 adalah $100 \%$, P7 semua peserta menjawab puas untuk menambah wawasan, pengetahuan, keterampilan dan keahlian peserta sehingga hasil untuk P7 adalah 100\%, kemudian untuk P8 dan P9 yang masing-masing perihal merasa puas dengan kegiatan pengabdian masyarakat dan Kegiatan pengabdian masyarakat yang diselenggarakan STMIK Nusa Mandiri sesuai dengan harapan mendapat hasil 100\%, dan terakhir P10 tentang kegiatan ini dapat diadakan kembali atau tidak, semua peserta menjawab puas sehingga hasil untuk P10 adalah 100\%.

Yang berarti bahwa kegiatan ini bisa dianggap sebagai kegiatan yang bermanfaat karena menambah pengetahuan serta wawasan bagi para peserta milenial tersebut, juga kegiatan ini dapat menambah keterampilan yang bisa dimanfaatkan langsung sesuai dengan pemahaman yang didapat serta dapat dikembangkan berdasarkan kreasi peserta.

\section{KESIMPULAN}

Hasil dan luaran yang dicapai pada kegiatan pengabdian masyarakat ini, pada umumnya peserta merasa senang dan dapat menambah pengetahuan dengan materi materi yang disampaikan oleh tutor. Walaupun ada kendala yang terjadi selama kegiatan berlangsung diantaranya ada beberapa peserta yang belum pernah mengakses youtube atau sosial media yang lain, sehingga tutor harus menjelaskan dari awal mengenai youtube dan sosial media. Beberapa saran yang diberikan kepada panitia diantaranya agar kegiatan serupa dilaksanakan rutin agar ilmu dan wawasan peserta dapat bertambah terutama di bidang teknologi.

Kegiatan ini sekaligus menjadi dorongan bagi peserta yang ada untuk mengaplikasikan ilmu yang didapat dari pelatihan sekaligus dan berkreasi serta mengembangkan lagi ilmu yang didapat sehingga dapat membuat konten yang bukan hanya menarik namun juga mendidik dan bermanfaat. Dengan demikian kegiatan ini secara tidak langsung menjadi bagian untuk turut menambahkan pengetahuan dan kemampuan sebagai bekal dalam mengerjakan konten gaya atraktif bagi anak-anak maupun remaja.

\section{UCAPAN TERIMAKASIH}

1. Remaja dan anak-anak RPTRA Alur Dahlia

2. Tim yang ikut berpartisipasi

\section{DAFTAR PUSTAKA}

[1] F. Amsury et al., "Workshop Pemanfaatan Market Place Dalam Menunjang Pemasaran Produk Pada Komunitas Mersi Fans Club Dimasa Pandemik Covid-19," AbdiMas Nusa Mandiri, vol. 2, no. 2, pp. 43-48, 2020.

[2] R. A. Purba et al., Teknologi Pendidikan, 1st ed., vol. 1. Jakarta: Yayasan Kita Menulis, 2020.

[3] E. Sindang, "Manfaat Media Sosial Dalam Ranah Pendidikan dan Pelatihan," Pusdiklat $K N P K$, vol. 1, no. 1, pp. 1-8, 2013.

[4] M. Pratama, "Peranan Video Editor Pada Konten Youtube SatuPersen," umn.ac.id, vol. 1, no. 1, 2020.

[5] S. Adinda and E. Pangestuti, "PENGARUH MEDIA SOSIAL INSTAGRAM @exploremalang TERHADAP MINAT BERKUNJUNG FOLLOWERS KE SUATU DESTINASI (SURVEI PADAFOLLOWERS @exploremalang)," J. Adm. Bisnis, vol. 72, no. 1, pp. 176-183, 2019.

[6] S. Kemp, "Digital 2020: Indonesia," datareportal.com, 2020. [Online]. Available: https://datareportal.com/reports/digital2020-indonesia.

[7] A. R. Rachmawati, "Lebih dari Separuh Kuota Data Digunakan Milenial untuk Mengakses Youtube," pikiran-rakyat.com, Bandung, p. Ekonomi, 19-Sep-2019.

[8] K. Lalo, "Menciptakan Generasi Milenial Berkarakter dengan Pendidikan Karakter guna Menyongsong Era Globalisasi," IImu Kepol., vol. 12, no. 2, pp. 68-75, 2018.

[9] N. A. Meinard, "Pemaknaan Kreator Konten Youtube: Studi Fenomenologi Kreator Konten Tim2one Chandra Liow Dan Usama Harbatah Memanfaatkan Media Baru," 2018.

[10] B. F. Wicaksono, M. Ibadurrahman, R. Ariansyah, and I. Handriani, "Sistem Aplikasi 'Pinda' Untuk Mencari Content Creator Menggunakan Metode Scrum," CESS Uournal Comput. Eng. Syst. Sci., vol. 4, no. 2, 
pp. 162-168, 2019.

[11] D. Ruth and D. A. Candraningrum, "Pengaruh Motif Penggunaan Media Baru Tiktok terhadap Personal Branding Generasi Milenial di Instagram," Koneksi, vol. 4, no. 2, p. 207, Oct. 2020.

[12] R. Yusri, S. Edriati, and R. Yuhendri,
"PELATIHAN MICROSOFT OFFICE EXCEL SEBAGAI UPAYA PENINGKATAN KEMAMPUAN MAHASISWA DALAM MENGOLAH DATA," RANGKIANG J. Pengabdi. Pada Masy., vol. 2, no. 1, pp. 3237, Aug. 2020. 